\title{
APLICAÇÃO DO CICLO PDCA PARA MELHORIA DO ENSINO A DISTÂNCIA - ESTUDO DE CASO: GESTÃO FLORESTAL DA UFPR
}

\author{
Ghislaine Miranda Bonduelle ${ }^{1}$, Setsuo Iwakiri ${ }^{2}$, Maura Regina Franco ${ }^{3}$, \\ Paulo Eduardo Sobreira Moraes ${ }^{4}$, Ana Cristina Follador ${ }^{5}$ \\ ${ }^{1}$ Eng. Florestal, Dr ${ }^{\mathrm{a}}$., Depto. de Eng. e Tecnologia Florestal, UFPR, Curitiba, PR, Brasil - ghislaine@ufpr.br \\ ${ }^{2}$ Eng. Florestal, Dr., Depto. de Eng. e Tecnologia Florestal, UFPR, Curitiba, PR, Brasil - setsuo@ufpr.br \\ ${ }^{3}$ Administradora de Empresas, Dr ${ }^{\mathrm{a}}$., Setor de Educação Profissional Tecnológica, UFPR, Curitiba, PR, Brasil - maurafranco@ufpr.br \\ ${ }^{4}$ Eng. Florestal, Dr., Setor de Educação Profissional Tecnológica, UFPR, Curitiba, PR, Brasil - paulomoraes@ufpr.br \\ ${ }^{5}$ Enga Química; M.Sc., Doutoranda em Eng. Florestal, Curitiba, PR, Brasil - anafollador@ gmail.com
}

Recebido para publicação: 23/10/2009 - Aceito para publicação: 15/12/2009

\begin{abstract}
Resumo
Este trabalho teve por objetivo principal aplicar o ciclo PDCA para quantificar, avaliar, analisar e buscar causas dos problemas enfrentados pelos alunos do Curso de Ensino a Distância, modalidade Gestão Florestal da UFPR, e propor ações de melhorias da qualidade de ensino com base nos resultados obtidos. A metodologia baseou-se no desenvolvimento do ciclo PDCA que é composto de quatro fases distintas: Planejamento, Desenvolvimento, Verificação e Ação. Foram utilizadas as seguintes ferramentas da qualidade do Ciclo PDCA: brain writting, gráfico de Pareto, gráfico de Ishikawa, métodos de análise de falhas e método $5 \mathrm{~W} 2 \mathrm{H}$ para a coleta de dados, análises e propostas de ações corretivas e de melhorias. Os resultados demonstraram que 56\% dos alunos entrevistados apontam o material didático como ponto negativo de maior impacto, seguido da falta de contato direto com o professor (22\%), falta de integração entre os participantes do curso (12\%) e autodisciplina e perseverança dos alunos (10\%). Entre as principais causas levantadas para a má qualidade do material didático estão: material muito extenso para a duração do curso e falta de aplicações práticas. Um plano de ação foi concebido para corrigir as falhas apontadas no levantamento.

Palavras-chave: Ensino a distância; PDCA; melhorias da qualidade.
\end{abstract}

\begin{abstract}
PDCA cycle application to improve remote education -study case: forest management at the UFPR. The main objective of this paper was to apply the PDCA cycle to quantify, evaluate, analyze, and find the causes of the problems appointed by the students of the Remote Education Course in Forest Management of Federal University of Paraná (UFPR) and to propose actions for improving the class quality based on the results. The methodology was based in the PDCA cycle development that is composed by four different phases: planning, development, verification, and action. The following quality tools were used in this work: brain writing, Pareto Graphic, Ishikawa Graphic, Fault Analysis Method, and 5W2H Method for the data collection, analysis and proposals of corrective actions and improvements. The results showed that $56 \%$ of the interviewed students pointed the instructional material as the main negative aspect, followed by the lack of integration among the participants of the course (12\%) and the student's self-discipline and perseverance (10\%). Among the main causes of the instructional material poor quality were: material too extensive to the course duration and lack of practical applications. An action plan was conceived to correct the deficiencies pointed out by the survey.
\end{abstract}

Keywords: Distance education; PDCA; improvements to the quality.

\section{INTRODUÇÃO}

Um dos grandes desafios das organizações atualmente é manter os processos e produtos padronizados, para que se possa chegar ao maior índice de qualidade e produtividade com a menor perda possível. Portanto a organização deve se adaptar às várias mudanças de mercado, o que acaba por exigir novas abordagens no seu sistema de gestão. Procedimentos que consistem em fontes de sucessos na 
prática das empresas precisam ser investigados, para que possam ter melhores entendimentos no sentido de serem aperfeiçoados e a difusão de sua correta aplicação na organização possa trazer melhores resultados.

Um dos procedimentos importantes conhecidos na gestão da qualidade total (TQM) é o uso do ciclo PDCA (Plan, Do, Check, Action), desenvolvido em 1920 por Walter Shewhart e popularizado por W. Edwards Deming (BONDUELLE, 2006). É uma metodologia que tem como função básica o auxílio no diagnóstico, análise e prognóstico de problemas organizacionais, sendo de importância fundamental para a solução de problemas. Poucos instrumentos se mostram tão efetivos para a busca do aperfeiçoamento quanto esse método de melhoria contínua, tendo em vista que ele conduz a ações sistemáticas que agilizam a obtenção de melhores resultados, com a finalidade de garantir a sobrevivência e o crescimento das organizações (PACHECO, 2009).

Por meio de suas etapas, espera-se que os resultados obtidos, e também o próprio processo em si, sejam melhorados, formando uma espiral de qualidade ascendente. Seguir o ciclo PDCA é mais eficaz do que adotar uma abordagem perfeccionista de se concentrar exclusivamente no desenvolvimento de processos perfeitos (JURAN, 1998).

A essência do ciclo PDCA é a ideia de que as saídas de um processo geralmente formam parte das entradas do processo subsequente, formando um circuito de realimentação de informações para a tomada de decisões sobre o controle da qualidade do processo (MELLO, 2006; JURAN, 1998; CAMPOS, 1994).

A forma mais utilizada do ciclo PDCA é o circuito de quatro etapas: Plan (planejar), Do (executar), Check (verificar) e Act (atuar corretivamente) (BANAS QUALIDADE, 2005; JURAN, 1998).

De acordo com Juran (1998) e Mello (2006), o ciclo PDCA é realizado na seguinte sequência:

- Planejar - são estabelecidos os objetivos e processos a serem controlados para alcançar os resultados pretendidos, com a finalidade de atender os requisitos do cliente e as políticas do próprio sistema de gestão.

- Fazer - implica a implementação dos processos.

- Verificar - é a fase em que os processos e seus resultados são registrados e avaliados quanto ao atendimento às políticas, objetivos e requisitos estabelecidos para o produto ou serviço.

- Atuar corretivamente - inclui a seleção e tomada de ações corretivas para evitar a repetição de situações indesejáveis ou não-conformes com os requisitos estabelecidos.

Kano; Kondo, citados por Juran (1998), afirmam que é importante observar que existem dois tipos de ações corretivas: temporárias e permanentes. As ações temporárias visam exclusivamente os resultados, enquanto as ações permanentes se voltam para os processos. Uma vez que as ações corretivas temporárias consistem no ajuste ou no retrabalho dos resultados não-conformes, podem ser implementadas sem que se saibam as causas da ocorrência da não-conformidade. As ações corretivas permanentes consistem na investigação da não-conformidade, a fim de se identificar e atuar sobre suas causas, evitando sua recorrência. As ações corretivas permanentes podem, a princípio, parecer insignificantes quando tomadas isoladamente, mas, quando analisadas em conjunto, resultam em significativas melhorias no processo.

O ciclo PDCA não é utilizado apenas para diagnosticar não-conformidades, mas também para evitar que elas aconteçam. Isso implica a tomada de ações preventivas, que atuam antes que o problema ocorra.

Figueira (2007) afirma que o giro completo do PDCA só acontece de forma adequada quando o registro de não-conformidades potenciais é maior que o de não-conformidades reais. Isso porque, estatisticamente, sempre ocorrem muito mais "quase falhas" do que falhas.

Ainda de acordo com Figueira (2007), a operação ideal de um sistema de gestão da qualidade tem como foco situações controladas de não-conformidades potenciais, garantindo a eficácia e a eficiência dos processos. $\mathrm{O}$ equilíbrio inteligente entre eficácia e eficiência aumenta a probabilidade do cliente do processo ficar satisfeito, a partir do uso adequado dos recursos disponíveis para tal.

Este trabalho teve por objetivos aplicar o ciclo PDCA para detectar, quantificar, avaliar, analisar e buscar as causas dos problemas enfrentados pelos alunos do Curso de Gestão Florestal da UFPR, modalidade ensino a distância, e propor ações de melhorias da qualidade de ensino com base nos resultados obtidos. 


\section{MATERIAL E MÉTODOS}

Amostragem

O público-alvo desta pesquisa foi um grupo de 81 estudantes do Curso de Pós-Graduação a Distância em Gestão Florestal, participantes do fórum de discussão na disciplina de Gestão da Qualidade Total.

\section{Pesquisa exploratória}

$\mathrm{O}$ fórum foi realizado em meio digital e todos os participantes tiveram acesso à opinião expressada pelos colegas.

A metodologia utilizada para a realização da pesquisa, baseada em Trindade (2000), encontra-se, de forma resumida, a seguir:

1. Coleta de opinião e avaliação junto aos alunos do Curso de Gestão Florestal a distância:

Através de um fórum de discussão disponibilizado no site do curso, os alunos foram convidados a enumerar os pontos positivos e negativos do curso a distância.

Ferramenta aplicada: brainwritting

A técnica do brainwritting foi adaptada neste caso, mas seguiram-se as duas fases-padrão da metodologia.

Fase 1 - produção das ideias: consistiu na tomada da opinião dos alunos através do fórum de discussão, o que ocorreu de forma livre e sem interferência. Os alunos expressavam por escrito suas ideias no site do fórum e essas ideias eram compartilhadas pelos colegas.

Fase 2 - exploração das ideias: foi realizada pelo professor da disciplina, que elencou as ideias e fez o levantamento da frequência de cada uma delas.

2. Estabelecimento dos grupos de afinidades:

Aquelas que apresentavam afinidades foram agrupadas em famílias, ou seja, a ideia central representava a cabeça da família das ideias.

Ferramentas utilizadas:

Diagrama de afinidades

Gráfico de Pareto por ordem de frequência

Considerando a frequência porcentual de cada família, foi construído o Gráfico de Pareto por ordem de frequência, cuja metodologia está descrita a seguir nas seguintes etapas:

a) Definição dos parâmetros a serem analisados: pontos negativos do curso a distância.

b) Definição do tempo a ser considerado: 10 dias corridos, período em que o fórum de discussão ficou no ar.

c) Construção da tabela contendo as seguintes informações: ponto negativo/agrupamento, número de respostas, frequência (\%), frequência acumulada (\%).

d) Construção do Gráfico de Pareto por frequência com dados referentes aos pontos negativos no eixo horizontal e o percentual de ocorrência no eixo vertical.

e) Construção sobre o eixo horizontal das barras representativas das observações contidas na tabela de frequências definida anteriormente, em ordem decrescente.

f) Desenho da linha relativa à frequência acumulada das observações realizadas.

3. Construção do Gráfico de Pareto por ordem de prioridade:

Nessa fase, utilizou-se a ferramenta de Pareto por prioridade, somente com os pontos negativos classificados por ordem de prioridade de resolução, segundo a visão dos alunos. Essa variação do Gráfico de Pareto consiste em atribuir pesos aos problemas, classificando-os por ordem de importância, independentemente da frequência com que apareceram nas respostas.

Após a realização dos agrupamentos das ideias, estes foram disponibilizados no fórum de discussão, para os alunos atribuírem pesos de acordo com a sua percepção da importância do ponto negativo.

As quatro classes de pesos utilizadas foram:

- Não-conformidades (defeitos/problemas) críticas (C): peso 10

- Não-conformidades maiores (M+): peso 5

- Não-conformidades menores (M-): peso 2

- Não-conformidades secundárias (S): peso 1 
O cálculo foi realizado da seguinte forma:

$$
v p=\frac{P a l 1 * F r 1+P a 2 * F r 2+\cdots, P a l n * F r n}{\sum n a l}
$$

Em que: $\mathrm{VP}=$ valor ponderado

$\mathrm{Pal}_{1}=$ peso atribuído pelo aluno 1

$\mathrm{Pal}_{2}=$ peso atribuído pelo aluno 2

$\mathrm{Pal}_{\mathrm{n}}=$ peso atribuído pelo aluno $\mathrm{n}$

$\mathrm{Fr}_{1}=$ Frequência da resposta 1

$\mathrm{Fr}_{\mathrm{n}}=$ Frequência da resposta $\mathrm{n}$

$\mathrm{Na}_{1}=$ total de alunos opinantes

Novamente as respostas foram analisadas e estratificadas, agora pela frequência ponderada, ou seja, a frequência com que o ponto negativo apareceu e o peso atribuído nas respostas. De posse desses resultados, foi estabelecido um novo Pareto, seguindo a metodologia da construção do Gráfico do Pareto por frequência descrita anteriormente.

4. Análise de causas e busca de soluções:

Os alunos foram convidados a opinar sobre as causas dos problemas levantados. Nesse item, alguns professores também opinaram.

Ferramentas utilizadas: brainwritting, Ishikawa, Método de Análise de Falhas, 5W2H

a) Gráfico de Ishikawa ou espinha de peixe:

O Diagrama de Ishikawa ou espinha de peixe é uma ferramenta que pode ser utilizada para se chegar a uma análise eficiente de uma não-conformidade. O resultado obtido com essa ferramenta ajudará a originar o ciclo PDCA, pois esse diagrama possibilita uma análise profunda das causas que originam os problemas (SIMÕES; RIBEIRO, 2009).

Para a construção do gráfico, necessitou-se da aplicação do brainwritting para se encontrar o maior número possível de causas que possam ter contribuído para gerar o ponto negativo.

Em seguida, essas causas são analisadas e inter-relacionadas, tentando-se chegar à causa-raiz ou fundamental do problema.

b) Método de Análise de Falhas:

Essa técnica também foi utilizada para a busca de causas dos pontos negativos.

Consiste em questionar uma atividade perguntando o porquê dessa atividade. Da resposta deverá ser originada uma nova pergunta usando o porquê.

c) Método $5 \mathrm{~W} 2 \mathrm{H}$

Excelente ferramenta de análise cujo objetivo é direcionar a discussão em um único foco, evitando a dispersão das ideias.

Essa ferramenta é útil em duas situações distintas de análise:

1. Verificação da ocorrência de um problema;

2. Elaboração de um plano de ação.

A técnica consiste em equacionar o problema, descrevendo-o por escrito. A descrição mostra como o problema é sentido naquele momento particular: como afeta o processo e as pessoas, que situação desagradável ele causa. A descrição deve considerar os aspectos relacionados à análise de problemas e plano de ação conforme apresentado na tabela 1.

Tabela 1. Análise de problemas e plano de ação pelo método 5W2H.

Table 1. Analys of problems and action plan by $5 \mathrm{~W} 2 \mathrm{H}$ method.

\begin{tabular}{lc}
\hline Análise de problemas & Plano de ação \\
\hline O que aconteceu? & O que será feito? \\
Quem era o responsável? & Quem será o responsável? \\
Por que aconteceu? & Por que será feito? \\
Onde aconteceu? & Onde será feito? \\
Quando aconteceu? & Quando será feito? \\
Como aconteceu? & Como será feito? \\
Quanto custou? & Quanto custará? \\
\hline
\end{tabular}




\section{RESULTADOS E DISCUSSÕES}

Os resultados demonstraram que $59,4 \%$ dos problemas detectados pelos alunos estão relacionados à metodologia e ao material didático, conforme pode ser observado na figura 1 . As reclamações mais frequentes dos alunos com relação à metodologia foram:

- O ensino a distância sem a presença física do professor provoca uma sensação de abandono nos alunos, levando a uma menor dedicação aos estudos.

- O material didático, que pode apresentar erros, como falta de digitação de fórmulas, falta de clareza ou, ainda, com excesso de conteúdo, leva à falta de tempo hábil para o aluno dedicar-se ao estudo. Deve-se considerar que a maioria dos alunos matriculados nesse curso trabalha em tempo integral, e o tempo para cada módulo é curto (um mês), tendo como consequência o acúmulo de material a ser estudado e exercícios a serem resolvidos.

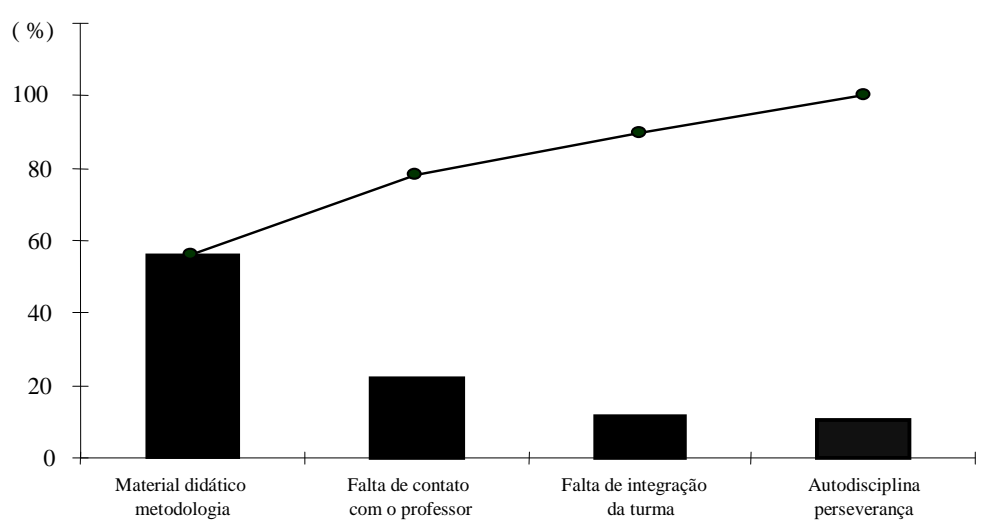

Figura 1. Principais problemas apontados pelos alunos do curso de Gestão Florestal a distância.

Figure 1. Main problems appointed by students of distance education in forestry management.

De acordo com a pesquisa, os demais problemas apontados foram a falta de contato direto com o professor, a falta de integração da turma e a falta de disciplina e perseverança por parte dos alunos, perfazendo um percentual próximo de $40 \%$ do total.

Observa-se, na pesquisa, um paradoxo, pois três das quatro principais reclamações são muito características de um curso a distância. Por exemplo, espera-se que um aluno que trabalha em tempo integral e que se propõe a realizar um curso de especialização no mesmo espaço de tempo que um curso presencial tenha a consciência de que terá de abrir mão de outras atividades, tais como lazer e horas com a família. Não se discute aqui a importância de uma ou outra atividade, mas a prioridade momentânea estabelecida a partir do objetivo proposto: realizar um curso de especialização a distância.

Por representar a maioria das reclamações dos alunos, novo brainwritting foi realizado para desdobrar o item "Material didático e Metodologia", e os resultados obtidos estão apresentados na tabela 2 .

De acordo com os dados apresentados na tabela 2, pode-se observar que cinco dos 15 problemas avaliados correspondem a quase $80 \%$ do total das reclamações dos alunos, ou seja, $30 \%$ das causas são responsáveis por $80 \%$ das reclamações dos alunos. O gráfico demonstra que as ações corretivas devem ser aplicadas prioritariamente nos seguintes problemas: falta de aplicações práticas, material extenso $\mathrm{x}$ tempo curto de curso, usar mais o "chat", melhorar a qualidade das videoaulas e promover maior número de encontros presenciais.

De posse da tabulação desses dados, foi realizado um novo brainwritting, solicitando-se que os alunos atribuíssem pesos para cada não-conformidade detectada, independentemente da frequência obtida para cada problema. Isso foi realizado porque nem sempre a não-conformidade mais frequente é a que tem o maior impacto no processo. Lembrando que as quatro classes de pesos utilizadas foram:

- Não-conformidades (defeitos) críticas (C): peso 10

- Não-conformidades maiores (M+): peso 5

- Não-conformidades menores (M-): peso 2

- Não-conformidades secundárias $(\mathrm{S})$ : peso 1 
Pode ser observada na tabela 3 a tabulação dos 15 itens do brainwritting do item "Material didático e Metodologia", agora levando em conta sua prioridade, ou seja, a conjugação da frequência com o peso a ele atribuído.

Tabela 2. Tabulação dos dados e frequência acumulada.

Table 2. Tabulation of data and cumulated frequency.

\begin{tabular}{lcccc}
\hline Item & Material didático / Metodologia & $\mathbf{N}^{\mathbf{0}}$ respostas & Frequência (\%) & $\begin{array}{c}\text { Frequência } \\
\text { acumulada }(\%)\end{array}$ \\
\hline 1 & Falta de aplicações práticas & 14 & 19,7 & 19,7 \\
2 & Material extenso x tempo de curso & 13 & 18,3 & 38 \\
3 & Usar mais o chat & 11 & 15,5 & 53,5 \\
4 & Melhorar videoaulas & 12 & 14,1 & 67,6 \\
5 & Mais encontros presenciais & 8 & 11,3 & 78,9 \\
6 & Escolha do tema TCC no início & 2 & 4,2 & 83,1 \\
7 & Nivelamento & 2 & 2,8 & 85,9 \\
8 & Custos e deslocamentos & 2 & 2,8 & 88,7 \\
9 & Atraso na entrega do material & 2 & 2,8 & 91,5 \\
10 & Mural pessimista/sem interesse & 1 & 1,4 & 93,0 \\
11 & Material complementar & 1 & 1,4 & 94,4 \\
12 & Formatação material & 1 & 1,4 & 95,8 \\
13 & Falta de acesso à biblioteca UFPR & 1 & 1,4 & 97,2 \\
14 & Erros materiais & 1 & 1,4 & 98,6 \\
15 & Avaliação pelo fórum & 1 & 1,4 & 100 \\
\hline
\end{tabular}

Tabela 3. Tabulação dos dados ponderados.

Table 3. Tabulation of weighted data.

\begin{tabular}{lccccccc}
\hline & & & & \multicolumn{2}{c}{ Frequência } & \multicolumn{2}{c}{ Frequência (\%) } \\
\cline { 7 - 8 } & Descrição & Class. & Peso & Absoluta & Ponderada & Ponderada & $\begin{array}{c}\text { Ponderada } \\
\text { acumulada }\end{array}$ \\
\hline 2 & Material extenso x tempo curto & $\mathrm{C}$ & 10 & 13 & 130 & 29,8 & 29,8 \\
5 & Mais encontros presenciais & $\mathrm{C}$ & 10 & 8 & 80 & 18,3 & 48,2 \\
1 & Falta de aplicações práticas & $\mathrm{M}+$ & 5 & 14 & 70 & 16,1 & 64,2 \\
3 & Usar mais o chat & $\mathrm{M}+$ & 5 & 11 & 55 & 12,6 & 76,8 \\
4 & Melhorar videoaulas & $\mathrm{M}+$ & 5 & 10 & 50 & 11,5 & 88,3 \\
14 & Escolha do tema TCC no início & $\mathrm{M}+$ & 5 & 2 & 15 & 3,4 & 91,7 \\
6 & Atraso na entrega do material & $\mathrm{M}-$ & 2 & 2 & 10 & 2,3 & 94,0 \\
7 & Erros no material & $\mathrm{M}-$ & 2 & 2 & 10 & 2,3 & 96,3 \\
9 & Mural pessimista/sem interesse & $\mathrm{M}-$ & 2 & 2 & 5 & 1,1 & 97,5 \\
11 & Nivelamento & $\mathrm{M}-$ & 2 & 1 & 2 & 0,5 & 97,9 \\
13 & Custos e deslocamentos & $\mathrm{M}-$ & 2 & 1 & 2 & 0,5 & 98,4 \\
15 & Material complementar & $\mathrm{M}-$ & 2 & 1 & 2 & 0,5 & 98,9 \\
8 & Falta acesso à biblioteca UFPR & $\mathrm{S}$ & 1 & 2 & 2 & 0,5 & 99,3 \\
10 & Avaliação pelo fórum & $\mathrm{S}$ & 1 & 1 & 2 & 0,5 & 99,8 \\
12 & Formatação do material & $\mathrm{S}$ & 1 & 1 & 1 & 0,2 & 100,0 \\
\hline Total & & & & 71 & 436 & 100,0 & \\
\hline
\end{tabular}

Pode-se observar que, pela percepção dos alunos, os maiores problemas no curso são o material extenso para um curto tempo de estudo, a falta de encontros presenciais, a subutilização do chat e a necessidade de melhorias nas videoaulas. Essas reclamações são as causas de $80 \%$ da insatisfação dos alunos no desenvolvimento do curso. 
Entre essas não-conformidades, o item que engloba o material extenso e o tempo curto para leitura desse material mais a obrigatoriedade de realização dos exercícios propostos é a não-conformidade de maior impacto no aproveitamento do curso, com 29,9\% das opiniões (ver dados da Tabela 3).

Em um segundo momento, os alunos percebem que nos encontros presenciais existe a possibilidade de tirar dúvidas, obtendo as respostas em tempo real, e ter a chance de interagir com os colegas, aumentando o aproveitamento da aprendizagem. Além disto, o contato direto com o professor pode provocar no aluno uma maior empatia pela disciplina.

O item "Material extenso x tempo curto" de cada módulo foi analisado pelos Métodos 5W2H, Ishikawa e análise de falhas, visando buscar a causa fundamental do problema.

\section{Análise de causas pelo método 5W2H}

A seguir são apresentadas as análises de causas resultantes da aplicação do método $5 \mathrm{~W} 2 \mathrm{H}$, com perguntas e respostas na sequência:

- O que aconteceu?

No curso de gestão florestal, a maioria dos alunos apontou como ponto negativo o material excessivamente extenso para um curto período de tempo de cada módulo.

- Por que aconteceu?

Como o material é extenso e o tempo de estudo é curto, os alunos não conseguem vencer o conteúdo do módulo.

- Como aconteceu?

Os professores entendem que, como o curso não é presencial, devem propiciar um maior número de informações para os alunos.

- Quando aconteceu?

Durante o Curso de Gestão Florestal.

- Onde aconteceu?

Na UFPR, no Curso de Gestão Florestal a distância.

- Quem eram os responsáveis?

A tutoria do Curso de Gestão Florestal, juntamente com o coordenador e o professor de cada disciplina.

- Quanto custou?

Custou o tempo de trabalho do professor responsável pelo módulo, o tratamento das reclamações, as horas e recursos despendidos pelos discentes, além dos custos indiretos, como a perda da imagem do curso pelo cliente e outros custos suportados pelos clientes, como gastos com material e compra de literaturas complementares mais direcionadas, entre outros.

Esse método proporciona uma visão genérica do problema, fato importante para se iniciar a sua análise, porém, para a busca da causa de um efeito indesejado, é necessária a aplicação de ferramentas mais específicas para a análise, como o gráfico de Ishikawa.

\section{Gráfico de Ishikawa}

O gráfico de Ishikawa apresentado na figura 2, ou causa-efeito, demonstra de maneira genérica as alegações, do ponto de vista dos alunos, aplicadas para o problema detectado.

O resultado obtido pelo Gráfico de Ishikawa mostrou que, para o efeito indesejado "Material extenso x tempo de estudo curto", deverão ser aplicadas ações corretivas no material e que os alunos terão que repensar suas horas de lazer e a organização de seu tempo.

Para reforçar se realmente essas causas são as fundamentais dos problemas apresentados, aplicou-se o Método de Análise de Falhas.

\section{Método de Análise de Falhas}

O Método de Análise de Falhas foi aplicado para aprofundar a análise das causas dos problemas, como descrito a seguir:

Por que o material do módulo é extenso e o tempo é curto?

Foram obtidas três respostas, que são apresentadas a seguir: 
- Porque o professor imagina que os alunos deverão ter o maior número de informações pelo fato de o curso não ser presencial.

Pergunta: Por que o professor imagina que os alunos deverão ter um maior número de informações escritas?

Resposta: Por falta de experiência com ensino a distância.

Ação genérica: treinamento dos professores em ensino a distância.

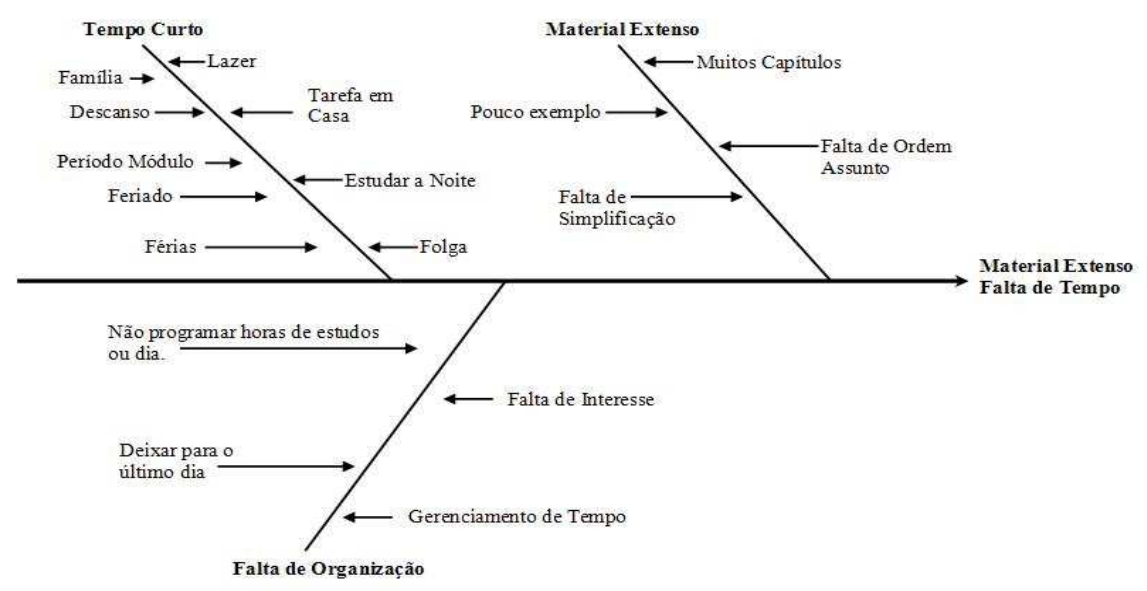

Figura 2. Gráfico de Ishikawa para o efeito "Material extenso para curto intervalo de tempo".

Figure 2. Graphic of Ishikawa for the effect of "Large study notes for short time".

- Porque os módulos são apresentados de forma contínua, sem intervalo entre um e outro módulo para término das atividades solicitadas.

Pergunta: Por que os módulos são apresentados de forma contínua?

Resposta: Devido ao modelo preconcebido de duração do curso.

Ação genérica: a Coordenação, em conjunto com a Tutoria, deverá realizar uma análise crítica do curso.

- Por falta de otimização do tempo de estudo por parte dos alunos.

Pergunta: Por que falta a otimização do próprio tempo?

Resposta: Porque existe falta de organização e interesse por parte dos alunos. estudo.

Ação genérica: os alunos deverão se conscientizar da importância da atividade de

Portanto, podem-se aqui delinear as seguintes ações corretivas mais detalhadas:

- Promoção de encontros entre professores do ensino a distância, visando a troca de experiências positivas.

- Supervisão da Coordenação junto a cada professor, verificando a qualidade do material apresentado e mostrando sugestões de melhorias desse material.

- Reformatação do modelo do curso, introduzindo semanas de recuperação ou o intervalo de alguns dias entre cada módulo.

- Busca de meios de motivação para os alunos, bem como um maior acompanhamento por parte da tutoria de cada aluno. Por exemplo: se o aluno deixou de entregar um exercício exigido, entrar em contato com ele imediatamente, para verificar quais dificuldades porventura surgiram e que poderiam ser sanadas.

- Predisposição do aluno a abrir mão do lazer e de férias sempre que for necessária uma maior dedicação aos estudos.

- Organização dos alunos para estudar um pouco todos os dias, por exemplo, uma hora ou uma hora e trinta minutos por dia. 
Os resultados apontam que um plano de ação deve ser estruturado e detalhado, para que possa ser implantado. O plano de ação foi realizado somente para o item "Material didático extenso". Na tabela 4 está apresentado o resumo do problema identificado.

Tabela 4. Resumo do problema identificado.

Table 4. Sumary of identified problem.

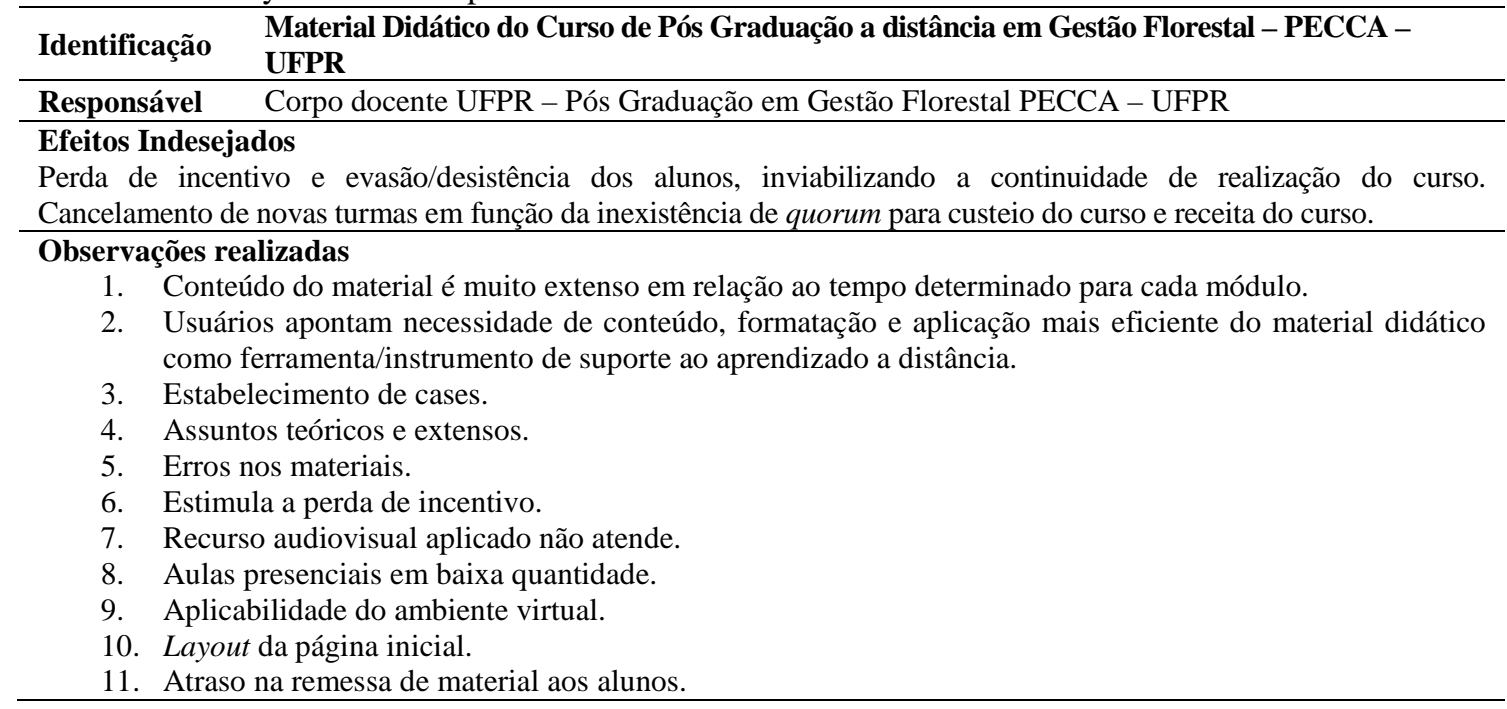

Plano de ação para a administração do curso

A seguir, apresenta-se um protocolo com plano de ação para a administração do curso a distância em gestão florestal:

- O que será feito?

R: Reestruturação do conteúdo e forma de apresentação do material.

- Por que será feito?

R: Porque o atual material, segundo avaliação dos alunos, não se encontra adequado ao curso.

- Como será feito?

R: Em etapas, pelo corpo docente, com suporte de pessoas especializadas nas diversas áreas.

- Quem será o responsável?

R: O professor da disciplina, supervisionado pelo Coordenador do Curso de Pós-Graduação em Gestão Florestal.

- Quando será realizado?

R: De $1^{\circ}$ de setembro de 2007 a $1^{\circ}$ de maio de 2.008 (início da próxima turma).

\section{Plano de ação para o aluno}

O plano de ação voltado para o aluno deverá seguir o seguinte protocolo:

- O que será feito?

R: O aluno deverá se organizar mais em seus estudos, gerenciando-os, para não deixar acumular estudos para o final.

- Como será feito?

R1: Abrir mão do lazer e descanso, sempre que necessário para o estudo.

R2: Não deixar de estudar nas férias, pois esse tempo parado lhe fará falta.

R3: Estudar um pouco à noite.

R4: Por último, ter autodisciplina, com força de vontade e determinação para continuação da pós-graduação.

- Quando será feito?

R: Entre maio de 2008 e abril de 2009.

- Por que será feito? 
R: Para que o aluno consiga atingir o objetivo, que é a conclusão do Curso de Gestão Florestal a distância no prazo previsto.

- Quem será o responsável?

R: Os alunos, a tutoria, os professores e a coordenação do curso.

Tabela 5. Cronograma do plano de ação.

Table 5. Schedule of action plan.

\begin{tabular}{|c|c|c|c|c|}
\hline $\begin{array}{l}\text { Etapas } \\
\text { (o quê?) }\end{array}$ & $\begin{array}{c}\text { Respostas } \\
\text { (quem?) }\end{array}$ & $\begin{array}{c}\text { Objetivo } \\
\text { (como?) }\end{array}$ & Suporte & $\begin{array}{c}\text { Data } \\
\text { (quando?) }\end{array}$ \\
\hline Reunião & Coordenação & $\begin{array}{l}\text { Expor ao corpo docente do Curso de Pós- } \\
\text { Graduação em Gestão Florestal o projeto de } \\
\text { reformulação do atual material didático aplicado }\end{array}$ & & 01/09/07 \\
\hline \multirow{6}{*}{ Reformulação } & \multirow{6}{*}{ Professores } & $\begin{array}{l}\text { - Desmembrar o material em parte conceitual e } \\
\text { aplicada (estudo de casos/aulas práticas) }\end{array}$ & & $10 / 11 / 07$ \\
\hline & & - Sintetizar a parte conceitual & Pedagogia & $15 / 12 / 07$ \\
\hline & & - Reprogramação visual & TI & $15 / 01 / 08$ \\
\hline & & - Revisão de textos & & $15 / 02 / 08$ \\
\hline & & - Reformulação dos audiovisuais & TI & $15 / 02 / 08$ \\
\hline & & - Gravação de videoaulas & Com. Visual & $15 / 03 / 08$ \\
\hline Revisão geral & $\begin{array}{c}\text { Coordenação } \\
\text { Professores }\end{array}$ & & $\begin{array}{l}\text { Pedagogia } \\
\text { TI } \\
\text { Com. Visual } \\
\end{array}$ & $15 / 04 / 08$ \\
\hline Aplicação & Coordenação & & & 01/05/08 \\
\hline
\end{tabular}

\section{CONCLUSÕES} conclusões:

Os resultados das avaliações realizadas neste estudo de caso permitem apresentar as seguintes

- O ciclo PDCA mostrou-se uma excelente ferramenta de análise dos problemas do Curso de Gestão Florestal a distância. As ferramentas da qualidade permitem um direcionamento da discussão, visando maior aproveitamento sem perda do foco. A correta aplicação das ferramentas e das ações corretivas sugeridas contribuirá para diminuir o número de reclamações dos alunos, aumentando o grau de satisfação com relação às expectativas do curso.

- $\quad 59,4 \%$ dos problemas detectados pelos alunos no curso a distância em Gestão Florestal foram relacionados à metodologia e ao material didático. $\mathrm{O}$ desmembramento desse item mostrou que os maiores problemas do curso estão relacionados ao material extenso para um curto tempo de estudo, à falta de encontros presenciais, à má utilização do chat e à necessidade de melhorias nas videoaulas.

- A aplicação dos métodos de Ishikawa, 5W2H e Análise de Falhas como ferramentas da qualidade detectaram como causas fundamentais problemas relacionados à falta de treinamento dos professores em ensino a distância, à falta de análises críticas realizadas periodicamente pela coordenação do curso em conjunto com a tutoria e à falta da consciência da importância da atividade de estudo por parte dos alunos.

- Foram propostos dois planos de ação: um para ser aplicado pela Coordenação do Curso, no que se refere à reformatação do material didático, e outro para ser aplicado pelos alunos, relacionado à motivação e persistência nos estudos.

\section{REFERÊNCIAS}

BANAS QUALIDADE. As ferramentas da qualidade: aprendendo a aplicar para solucionar problemas. Curitiba: Epse, 2005. 1 CD-ROM.

BONDUELLE, G. M. Gestão da qualidade total para a produção florestal. Curitiba: UFPR/PECCA, 2006. 255 p. Apostila do Curso de Especialização a Distância em Gestão Florestal.

CAMPOS, V. F. TQC: controle de qualidade total (no estilo japonês). 5. ed. Belo Horizonte: Fundação Christiano Ottani, 1994. 150 p. 
FIGUERA, T. Quase tudo acontece antes de acontecer! São Paulo: Banas Qualidade, n. 180, p.58-59, 2007.

JURAN, J. M.; GODFREY, A. B. The quality control process. In: JURAN, Joseph M. (Co-ed.). Juran's quality handbook. $5^{\text {a }}$ ed. Nova Iorque: Mcgraw-Hill, 1998. p. 4-8.

KANO, N.; KONDO, Y. Quality in Japan. In: JURAN, Joseph M. (Co-ed.). Juran's quality handbook. $5^{\mathrm{a}}$ ed. Nova Iorque: Mcgraw-Hill, 1998. p. 41.3-41.5.

PACHECO, A. P. R. O Ciclo PDCA na Gestão do Conhecimento: uma abordagem sistêmica. Disponível em: <http://www.isssbrasil.usp.br>. Acesso em: 12/8/2009.

SIMÕES, L.; RIBEIRO, R. de C. Ciclo PDCA como ferramenta da qualidade total. PACHECO, A. P. R. O Ciclo PDCA na Gestão do Conhecimento: uma abordagem sistêmica. Disponível em: <http://www.unisalesiano.edu.br >. Acesso em: 12/8/2009.

TRINDADE, C. Ferramentas da qualidade: aplicação na atividade florestal. Viçosa, MG: UFV, 2000, $124 \mathrm{p}$. 
